\title{
Concepções de justiça e a análise de políticas públicas
}

\section{Conceptions of justice and the public policy analysis}

\author{
Camila Gonçalves de Mario \\ Doutora em Ciências Sociais pela Universidade Estadual de Campinas/SP e Pesquisadora do NEPPs - Núcleo de Estudos de Políticas Públicas / \\ Universidade Estadual Paulista Júlio de Mesquita Filho, camilagdemario@gmail.com \\ http://lattes.cnpq.br/4353113348878044
}

Resumo: Este artigo tem como objetivo propor uma análise das políticas públicas que leve em consideração questões normativas de justiça. Seu ponto de partida é a assunção de que as políticas públicas têm, dentre suas finalidades, garantir a justiça. Entende-se que as políticas públicas são instituições que distribuem bens e recursos sociais e são voltadas para a realização dos direitos fundamentais da cidadania, tarefa que tem importante impacto sobre a distribuição de bens e recursos em sociedade e, portanto, para a mitigação da desigualdade social. A partir dessa premissa e de uma breve apresentação de concepções de justiça basilares para a reflexão desenvolvida, este artigo propõe uma análise substantiva das políticas públicas a partir de concepções de justiça e apresenta duas perspectivas a partir das quais realizá-las: uma institucional-procedimentalista e outra a partir das ideias e valores que são fundamento das instituições e da ação política.

Palavras-chave: políticas públicas; teorias da justiça; justiça social.

Abstract: This article aims to propose an analysis of public policies that take into account the normative issues of justice. The starting point is the assumption that public policies have among their goals to promote justice. Public policies are understood as institutions that distribute goods and social resources and seek the realization of fundamental rights, a task that has an important impact on the distribution of goods and resources in society and thus in the mitigation of social inequality. Considering this premise, and coming from a brief presentation of main conceptions of justice for the developed reflection, this article proposes a substantive analysis of public policies and presents two perspectives from which they are to be carried out, one being institutionalist-procedural, and the other being based on the ideas and values that constitute the foundations of institutions and of the political action.

Keywords: public policies; theory of justice; social justice.

Texto completo em português: http://www.apgs.ufv.br Full text in Portuguese: http://www.apgs.ufv.br

\section{Introdução}

Este artigo tem como objetivo propor uma análise das políticas públicas que leve em consideração questões normativas de justiça. A premissa básica que constitui o ponto de partida dessa proposta é a assunção de que as políticas públicas têm importante conexão com questões de justiça. Entende-se que as políticas públicas são instituições que distribuem bens e recursos sociais e são voltadas para a realização, bem como para a garantia, dos direitos fundamentais da cidadania.

Ressalto que, nessa perspectiva, estou considerando as políticas públicas, instituições da estrutura básica da sociedade, para além de seu viés distributivista, ou redistributivista, e pensando a justiça como um princípio de fundo orientador das ações do Estado e das relações sociais, o que nos permite pensar a justiça para além do escopo de atuação das políticas sociais.

Sob essa perspectiva, é fundamental pensar sobre a justiça dos propósitos, procedimentos e resultados alcançados pelas políticas públicas. Proponho, dessa forma, uma análise substantiva da justiça, que leve em consideração preocupações normativas que devem ser somadas a análises de cunho procedimental e empiricista, mais preocupadas com as condições materiais de produção da política.

A justiça é preocupação que sempre esteve presente na teoria social e política; entretanto, a produção recente das ciências sociais e de análise de gestão e políticas públicas não tem debatido e tematizado sua dimensão de forma a promover uma análise semântica e ontológica de seus sentidos e de sua importância para o entendimento e crítica das democracias contemporâneas.

Especificamente no caso brasileiro, o processo de redemocratização vivido nos anos 1980 e 1990 trouxe fortes de demandas de justiça social, presentes tanto nas demandas por institucionalização e reconhecimento de direitos de cidadania quanto nas demandas de reforma do Estado, que culminaram na descentralização das políticas públicas e na institucionalização de uma democracia participativa cujos contornos são peculiarmente brasileiros. Esse processo foi reconhecido pelas ciências sociais como o surgimento de novos atores que demandavam o "direito a ter direitos", o que instaurou uma nova gramática social na sociedade brasileira.

No que se refere à reforma do Estado, é importante ressaltar que essa se deu em meio a uma disputa de projetos políticos com orientações normativas de justiça distintas, diria antagônicas, resultando em uma configuração que carrega em si traços democráticos e liberais-igualitários e, ao mesmo tempo, neoliberais. As demandas por descentralização do Estado, via fortalecimento do poder local, e por participação na elaboração e implementação de políticas públicas, carregavam em si uma demanda por mais justiça social, pois a aposta era a de que a proximidade entre governo e sociedade civil, que a transparência dos atos e ritos do Estado e a possibilidade de escuta das reais necessidades da população, propiciaria políticas públicas com 
resultados mais justos, capazes de diminuir as desigualdades sociais, a pobreza e de empoderar o cidadão.

Em suma, mais do que uma questão de organização do Estado e de estabelecimento de procedimentos e instrumentos democráticos de gestão estava em jogo uma demanda normativa por justiça social por meio de políticas públicas que fato promovessem qualidade de vida e distribuição de recursos.

Este artigo busca, a partir da teoria da justiça de John Rawls, propor uma análise de políticas públicas que leve questões de justiça em consideração. Propõe-se que as teorias da justiça constituam um parâmetro normativo de análise, levando em consideração as diferenças de contexto social e histórico entre aqueles que embasaram a formulação das teorias da justiça aqui apresentadas e aquele que caracteriza a sociedade brasileira.

O intuito é buscar, nas teorias da justiça, parâmetros que nos permitam tematizar e problematizar o justo, e a partir deles entender quais são as concepções de justiça em jogo na sociedade brasileira e presentes nas políticas públicas. Os direitos e deveres sustentados pela Constituição do Brasil e os valores morais que os embasam dialogam diretamente com os de outras democracias contemporâneas, ademais foram inspirados em experiências de outras sociedades, dentre elas a norte-americana e algumas europeias, sociedades essas que são pensadas pelos autores, teóricos da justiça, que serão apresentados ao longo deste artigo.

Para Rawls (2008, p. 4), a justiça é a mais importante virtude das instituições. Em uma sociedade justa, as liberdades da cidadania são irrevogáveis, e os direitos não estão sujeitos a negociações políticas e nem ao cálculo de interesses sociais.

Por mais que a teoria da "justiça como equidade" de John Rawls seja uma empreitada teórica, abstrata ${ }^{1}$, ela tem como ponto de partida questões fundamentais para as democracias capitalistas contemporâneas; aliás, Rawls (2008, p. 12) inicia seu trabalho afirmando que seu objetivo é tentar equilibrar aqueles que são os dois princípios fundamentais e ao mesmo tempo conflitantes dessas sociedades, a liberdade e a igualdade, para pensar caminhos que dentro dos moldes dessas sociedades nos levem a resultados mais justos. $O$ conceito de justiça se refere a esse equilíbrio entre exigências conflitantes, enquanto uma concepção de justiça deve ser entendida "como o conjunto de princípios correlacionados que objetiva identificar as considerações relevantes que determinam esse equilíbrio".

Destaco a definição de justiça de Rawls:

Acredito que o conceito de justiça é definido, então, pelo papel de seus princípios na atribuição de direitos e deveres e na definição da divisão apropriada das vantagens sociais. A concepção de justiça é uma interpretação desse papel. (Rawls, 2008, p. 12)

A análise de políticas públicas a partir de concepções de justiça que proponho busca justamente realizar uma interpretação dos princípios e valores morais fundantes da política, questionando seus objetivos e seu papel na distribuição de bens e recursos sociais. O desvelamento da concepção de justiça orientadora de nossas políticas públicas advém dessa interpretação, possibilitando uma avaliação substantiva de seus resultados e propósitos normativos dado o pano de fundo definidor dos objetivos da política expresso na Constituição e no desenho das próprias políticas públicas.

\section{1 - A teoria da justiça como equidade}

Inicio trazendo uma passagem de Beatriz Sarlo, de seu livro "Tempo Presente". Nesse livro, a autora reuniu vários ensaios e textos curtos escritos com o objetivo de pensar a mudança cultural argentina e o presente, como momento privilegiado de sua análise. Em um de seus capítulos, "A dívida", a autora trata da dívida que o Estado argentino contraiu com a sociedade ao não garantir os direitos com os quais se comprometeu, principalmente os direitos sociais; em sua opinião, o Estado agia como se não fosse responsável por milhões de pessoas não terem acesso aos seus direitos. Essa dívida, entretanto, não havia como ser negada, já que estava gravada nos corpos dos excluídos, dos credores da dívida não paga. Sarlo diz o seguinte:

uma sociedade não se sustenta apenas por suas instituições, mas, principalmente, por sua capacidade de gerar expectativas no tempo. O corpo e o tempo estão ligados: uma vida é um corpo no tempo. A dívida é também uma dívida de tempo porque, quando o corpo não recebe aquilo de que necessita, o tempo se torna abstrato, inapreensível pela experiência: um corpo que sofre sai do tempo da história, perde a possibilidade de projetar-se adiante, apaga os sinais de suas recordações. Os pobres têm corpos sem tempo. Por isso as mulheres que têm trinta anos, oito filhos e um marido desempregado ou preso parecem tão velhas. Por isso os corpos dos velhos pobres parecem tão aniquilados. Para eles, o tempo já se esvaiu por completo: nasceram, cresceram e envelheceram no hiato em que um jovem próspero entrar na etapa da maturidade. [...] Quando se rompe a expectativa de um tempo futuro, quando ninguém se sente mais credor e nem titular de direitos, os corpos usam a violência para se rebelar. A dívida social feriu os corpos. Estamos acostumados a pensar nos cidadãos de maneira abstrata. Seria melhor pensar neles a partir da materialidade explosiva das necessidades não atendidas (Sarlo, 2005 pp. 15-16)

Quando falamos em justiça, especificamente em justiça social, estamos falando justamente dessa capacidade de gerar expectativas no tempo, da capacidade que uma sociedade tem de gerar oportunidades para que seus cidadãos desenvolvam expectativas de vida, ao longo de toda a sua vida.

A justiça social não é tema isento de controvérsias e trata-se de um tema recente na tradição moderna ocidental, ao menos tal como estou propondo pensá-la aqui. Por detrás da ideia de gerar expectativas ao longo do tempo reside uma noção de justiça social que percebe a sociedade e o Estado como responsáveis pela garantia de uma justa distribuição de bens, recursos e riquezas que propicie iguais oportunidades a todos os cidadãos.

A noção de justiça distributiva invoca o Estado como garantidor dessa distribuição, um garantidor que vise satisfazer as necessidades de todos; a partir dessa exigência o debate se desenrola então em torno de quais recursos distribuir e como. Ponto crucial que justifica essa distribuição é justamente a 
constatação de que o mercado não consegue promover uma distribuição que garanta a todos uma ampla proteção de seu bemestar, sendo o Estado é chamado a corrigir as imperfeições do mercado. Ao requerer esse papel do Estado, estamos reconhecendo que os recursos em sociedade não devem ser distribuídos adotando o mérito individual como critério central, mas sim com base em uma noção de igualdade moral básica dos seres humanos.

John Rawls, referência obrigatória do debate normativo da justiça, coloca no centro de sua teoria a dimensão institucional das sociedades. Em sua teoria da justiça como equidade, afirma que a justiça é central para a cooperação social e que são as instituições da estrutura básica da sociedade que devem oferecer o suporte necessário para que as pessoas façam de suas vidas algo que consideram valioso. Ao fazer isso, a sociedade permitiria que as pessoas desenvolvessem também o respeito por si próprias, que é para Rawls o bem mais importante quando se trata de assegurar um status de igualdade.

Não terei aqui condições de tratar de maneira aprofundada a teoria ralwsiana. Trarei apenas alguns dos aspectos mais importantes: aqueles que constituem o cerne da teoria e, por isso, permitem-nos pensar a aproximação da teoria da justiça como equidade de Rawls e de outras concepções de justiça com a análise de políticas públicas.

A teoria de Rawls é uma abordagem contratualista, que propõe constituir uma base moral para as sociedades democráticas. Primeiro porque a teoria atribui aos indivíduos direitos iguais de participação; segundo porque seus direitos são formados a partir do entendimento público; e terceiro porque pretende orientar a razão política e os julgamentos de seus membros no exercício de seus direitos políticos.

O objeto principal da teoria da "justiça como equidade" de Rawls é a estrutura básica da sociedade e suas instituições. Os princípios da justiça propostos por Rawls se aplicam às instituições, mais precisamente, ao modo como estas distribuem os direitos e deveres fundamentais e como determinam a divisão das vantagens decorrentes da cooperação social. Já os indivíduos agirão de maneira justa, desde que seus atos estejam em conformidade com as exigências destas instituições.

Esses princípios da justiça na teoria de Rawls são acordados por pessoas que representam os cidadãos, esse momento de formulação do contrato social se dá a partir de uma formulação hipotética que Rawls chama de "posição original". As partes tomam sua decisão sob o "véu da ignorância", o que significa que elas desconhecem sua posição em sociedade, artifício pensado por Rawls como uma maneira de evitar que alguém tente levar vantagem, e garantir que os princípios decididos sejam aqueles que favorecerão ao máximo todos os cidadãos.

Os princípios acordados são dois; o primeiro tem como componente as liberdades e direitos fundamentais, e o segundo tem dois componentes e está voltado para as desigualdades em sociedade. São eles: (1) o princípio da diferença, para o qual somente deve-se admitir as desigualdades que favorecem o terço mais pobre da sociedade e (2) o da igualdade equitativa de oportunidades (IEO), para o qual os cargos e posições devem ser acessíveis a todos. $O$ primeiro princípio tem prioridade sobre o segundo e o princípio da IEO tem prioridade sobre o Princípio da Diferença.

Para Rawls, a distribuição natural não é justa nem injusta; justo ou injusto é como as instituições lidam com essa distribuição. Por isso ele afirma que a estrutura básica da sociedade tem influência decisiva sobre a realização das expectativas de vida dos cidadãos, sobre as oportunidades à disposição de cada um, e sobre a nossa capacidade de tirar proveito delas. O objetivo da estrutura básica é controlar e minorar as desigualdades provenientes das diferenças de "ponto de partida" entre os cidadãos, ou seja, de desigualdades dadas pelo nascimento, por condições econômicas e sociais que, por mínimas que sejam, incidem sobre as oportunidades e sobre as capacidades de realização ao longo das vidas dos cidadãos, com um efeito cumulativo (Rawls, 2007).

O argumento central de Rawls é o de que é preciso minimizar as desigualdades oriundas de diferenças de classe de origem, de talentos naturais e da sorte de cada um ao longo da vida. Para ele, mesmo em uma sociedade bem ordenada, nossas perspectivas de vida são afetadas por contingências, pela sorte e, também, pelo modo como a estrutura básica da sociedade faz uso dessas contingências para cumprir certas metas sociais. Portanto, não podemos ignorar as desigualdades e deixar que elas se manifestem sem regulamentações que preservem a justiça de fundo, questão fundamental para uma sociedade pensada como um sistema equitativo de cooperação entre cidadãos livres e iguais.

Rawls pensa a aplicação dos princípios da justiça em uma sequência de quatro estágios. O primeiro é a posição original, o segundo, o estágio constitucional, o terceiro, o legislativo e o quarto, o da aplicação das normas, sendo que o véu da ignorância vai sendo retirado ao longo desses estágios. O primeiro princípio é a meta do estágio constitucional e o segundo princípio deve ser o foco do estágio legislativo. Rawls propõe uma divisão de trabalho entre os estágios, em que cada estágio trata de diferentes questões de justiça social.

Essa divisão corresponde às duas partes da estrutura básica: em uma, o primeiro princípio é o padrão da convenção constitucional e, na outra, o segundo princípio regula o estágio legislativo, determinando

que as políticas sociais e econômicas visem maximizar as expectativas de longo prazo dos menos favorecidos, em condições de igualdade equitativa de oportunidades, desde que as liberdades iguais sejam preservadas. (...) assim, a prioridade do primeiro princípio da justiça em relação ao segundo se expressa na prioridade da convenção constituinte em relação ao estágio legislativo. (Rawls, 2008, p.245)

Dessa forma, no estágio legislativo, informações sobre os fatos sociais e econômicos devem ser conhecidos e o arcabouço legal deve atender aos princípios da justiça, principalmente ao 
segundo princípio, e a quaisquer limites impostos pela Constituição.

O quarto (e último) estágio, o da aplicação das normas judiciais por juízes e administradores a casos específicos, exige que o véu esteja completamente retirado e que todos tenham acesso às informações necessárias para que possam acompanhar a aplicação das normas. No entanto, diferentemente do que sua nomenclatura sugere, esse estágio não se restringe ao sistema judiciário: ele também envolve os cidadãos e suas decisões sobre o que as leis requerem deles.

Nesse estágio, os princípios da justiça concretizam-se, mediados pela Constituição democrática e por suas leis, resultando em determinações voltadas para o que indivíduos e instituições devem fazer em determinados casos.

Finalizo esta exposição sobre a teoria da "justiça como equidade" com a noção de "bens primários" trabalhada por Rawls. Esses são os bens distribuídos pela estrutura básica e necessários para que os cidadãos possam se desenvolver, exercer plenamente suas capacidades morais, e realizarem suas expectativas de vida. Os bens primários são:

1 - As liberdades básicas dadas por uma lista, por exemplo: liberdades de pensamento e consciência; liberdade de associação; e aquelas definidas pela liberdade e integridade do indivíduo, bem como as definidas por lei e, finalmente, as liberdades políticas;

2 - liberdade de movimento e de escolha de ocupação em oposição a um fundo (background) de diversas oportunidades;

3 - acesso a cargos de responsabilidade e a seus respectivos poderes e prerrogativas, particularmente aqueles em instituições políticas e econômicas centrais: 4 - renda e riqueza;

5 - as bases sociais do auto respeito autorrespeito ${ }^{2}$. (Rawls, 1999, p.363)

Os bens primários são uma faceta das instituições ou da situação dos cidadãos quando em relação com elas; é sempre bom lembrar que essas instituições são abertas ao acompanhamento e discussão pública.

O índice de bens deve ser usado como uma maneira de comparar a situação social dos cidadãos, posto que ele define uma base pública de comparação interpessoal que não deve ser usada indiscriminadamente, mas somente em situações nas quais surgem questões de justiça que têm como referência a estrutura básica da sociedade.

Rawls buscou formular uma teoria da justiça para sociedades democráticas, cuja característica central é o pluralismo doutrinário e ao mesmo tempo equilibrar dois valores morais centrais para tais sociedades a igualdade e a liberdade.

A liberdade é fundamental para a formulação de concepções de bem e para o exercício da cidadania; a igualdade não significa tratamento igual a todos e nem garantir uma igual distribuição de bens para todos, mas sim o reconhecimento de que todos os cidadãos são portadores de igual importância perante ao Estado.

Sugiro que aproximação com a análise de políticas públicas deve ser feita a partir da maneira como Rawls compreende o papel das instituições e o seu valor em sociedade. Para ele, instituições justas, condizentes com os princípios de justiça que são formulados tomando por base a concepção de pessoa (igual e entendida como um fim em si mesma, tal como formulado por Kant) se sustentam ao longo do tempo, porque as pessoas conhecem suas normas e sabem o que esperar delas, e das outras pessoas, quando em relação com as instituições. A hipótese fundamental é a de que um arranjo justo levará a um resultado justo, propiciando um comportamento justo.

\section{2 - A análise de políticas públicas pelo viés normativo da justiça}

Seguindo o raciocínio rawlsiano, as políticas públicas são as instituições responsáveis pela distribuição de bens e recursos em sociedade que garantirão a realização dos planos de vida das pessoas (1) ao mitigar as desigualdades dadas tanto pelo nascimento como pela posição de cada um em sociedade através de uma distribuição equitativa de bens e recursos e (2) ao garantir a Igualdade Equitativa de Oportunidades e a realização das expectativas de vida.

Podemos pensar a justiça de uma política pública a partir de diferentes vieses. Posso considerar uma política pública justa/injusta, em uma chave análise mais voltada para as preocupações do direito público, a partir da interpretação e da aplicação da Lei enquanto mecanismo garantidor de justiça em si, entendendo o Estado enquanto ente que tem o dever de cumprir a Lei por meio da implementação de políticas públicas. Se pensarmos no caso brasileiro, o dilema se instaura exatamente no cumprimento do dever e na realização do direito dos cidadãos.

Também posso pensar a justiça das instituições em outra chave de análise, normativa. No que se refere à análise de políticas públicas, proponho ao menos duas perspectivas: uma que adota como ponto de vista central a chave "institucionalprocedimentalista", voltada para a análise dos procedimentos, questionando se esses são claros, se são justos, legais, de acordo com as normas da própria instituição; e outra cujo ponto de partida é substantivo, ou seja, voltada para os valores sustentados pela política pública. Cabe, então, indagar como ambos, processo e substância, são ou não capazes de gerar um resultado justo.

Grande parte das análises de políticas públicas têm preocupações de ordem procedimentalistas, analisam processos de gestão, e/ou programas específicos com uma perspectiva de análise mais empírica, o que temos ainda é um predomínio de trabalhos descritivos cuja ênfase recai sobre a análise das estruturas e instituições e/ou dos processos decisórios de políticas setoriais específicas.

São em grande parte dos casos análises voltadas para a produção de dados empíricos, que como coloca Bo Rothstein, não acrescentam muito ao o que gestor já sabe, trata-se muito mais de uma sistematização da realidade, marcada pela falta de teorização. Falta de teorização que se explica pelo tipo de conhecimento que é próprio da análise de políticas públicas, voltado para a empiria e prática política. 
Para além das questões apontadas pela teoria de Rawls, considero que a aproximação do campo de análise de políticas públicas com a do campo das teorias da justiça se justifica também pelo fato de que a justiça tem aparecido como uma questão, embora não tematizada, que perpassa uma ampla gama de questões políticas e sociais.

Verifica-se essa tendência no campo de análises dos movimentos sociais e de participação social, pois os autores têm reconhecido como um dos objetivos dos movimentos sociais e dos espaços institucionalizados de participação a luta pela equidade, pelo desenvolvimento, pela efetividade de direitos e da cidadania e pela justiça social.

É possível também observar nas análises de políticas públicas a menção à importância da inclusão social, do desenvolvimento, da equidade e do combate à desigualdade e à pobreza. Questões que são todas ligadas à temática da justiça. Entretanto, ainda é preciso avançar em um debate teórico que dê suporte e referencie tais menções, demonstrando a necessidade de aproximar o debate conceitual da análise da política com o da justiça em suas diferentes dimensões, principalmente com a dimensão normativa, cujo debate vem-se dando em campo distinto e de maneira apartada da análise da ação política.

A dimensão do justo nas políticas públicas se revela essencialmente em seu viés distributivista, enquanto uma ação do Estado que realiza a distribuição de bens e recursos em sociedade voltado para a diminuição da desigualdade e da pobreza. O alcance dessa distribuição e seus resultados deveriam, ao menos idealmente, ser condizentes com a concepção de justiça sustentada pela sociedade e expressa na letra da Lei.

A conexão entre as teorias da justiça e a prática política ainda é incipiente, não só no campo acadêmico brasileiro. Wolgang Merkel (2007) é um dos autores que têm buscado mostrar quais conexões são possíveis pensando o que ele chama de uma "teoria da ação" que leve em consideração recomendações/orientações das teorias da justiça.

Merkel (2007) aponta que os estudos sobre as transformações sociais e a democracia na América Latina ou negligenciam ou ignoram completamente as teorias contemporâneas da justiça social. O termo "justiça social" aparece em trabalhos que na verdade lidam com o tema da desigualdade de renda, enquanto as diferenças entre "igualdade de renda" e "igualdade de oportunidades" sequer são trabalhados. Concepções como justiça social, desigualdade de renda, desenvolvimento social, surgem como se se referissem a mesma coisa, e seus reais sentidos desaparecem em uma névoa de sinônimos implícitos.

Merkel, buscando mediações que the permitam fazer a conexão entre as teorias da justiça e sua teoria da ação, deriva cinco pontos das teorias de John Rawls e Amartya Sen por ele considerados "preferências políticas da ação que são derivadas das teorias da justiça". São eles: (1) diminuição da pobreza; (2) investimento em educação e formação; (3) inclusão no mercado de trabalho; (4) estruturação de uma rede de segurança social para além do trabalho; (5) e a diminuição da desigualdade de renda e riqueza.

Tais preocupações, observa Merkel, são oriundas de uma concepção liberal igualitária de justiça e têm como finalidade a realização de meios voltados para a mitigação das desigualdades sociais, e, saliento, podem ser identificadas como preocupações que orientam o desenho e a implementação de nossas políticas públicas e sociais.

Retomando as perspectivas de análise possíveis, a análise das políticas públicas a partir de considerações de justiça - tanto de seus propósitos e como dos resultados da política - pode-se realizar por uma perspectiva mais institucionalista (procedimental) ou de uma perspectiva mais voltada em pensar o papel dos atores, das ideias e dos valores no processo da política (substantiva).

\section{1) Da instituição para os atores}

Nessa perspectiva nosso olhar estaria mais voltado para o papel desempenhado pela instituição como aquela que induz o comportamento das pessoas. A análise aqui questionaria quais concepções de justiça estão expressas no desenho da política, quais procedimentos devem ser idealmente adotados dados os objetivos da política e os resultados pretendidos, se esses procedimentos são transparentes e de conhecimento de todos, se realmente propiciam o resultado mais justo - perante os objetivos da política - e se os resultados alcançados são condizentes com aquilo que se entende por justo.

Trata-se de uma análise ampliada e que toma o justo como parâmetro para a análise e avaliação da política pública. Busca-se aqui fugir de uma análise excessivamente mecanicista, ou racionalista, do processo de implementação e que não permite acomodar a indeterminação inerente ao processo das políticas públicas.

O central aqui é adotar como ponto de partida da análise aquilo que o Estado deveria fazer (em termos normativos e adotando concepções de democracia e justiça como parâmetro) ao invés daquilo que o Estado pode fazer. Como coloca Rothstein (1998) aquilo que o estado pode fazer é um ponto de partida empírico que não pode ser simplesmente transformado em um ponto de partida normativo sem que haja uma análise normativa explícita.

Outro ponto importante a ser somado a essa análise é o que Rothstein chama de legitimidade da política e que se aproxima da preocupação de Rawls sobre a justiça das instituições que eu mencionei anteriormente. Trata-se da ideia de que os cidadãos devem confiar nas instituições políticas e confiar que os outros também confiam nelas. A legitimidade pode ser pensada considerando-se três diferentes aspectos: a tolerância da intervenção do Estado; se os indivíduos aceitam as decisões tomadas pelo Estado e, se há cooperação dos indivíduos com os Estados para alcançar as metas definidas.

A ideia aqui, novamente proveniente da teoria de Rawls, é a de que as instituições não só influenciam o que os atores políticos 
consideram uma ação racional a partir de seus próprios interesses, mas também o que eles entendem por um comportamento moralmente justificável.

Entretanto, para que os indivíduos atribuam valor moral para uma ação solicitada coletivamente ao menos três condições são necessárias:

1- que os cidadãos vejam o programa como justo. Isso significa que medidas públicas não podem ser tomadas apenas considerando o julgamento de profissionais da área ou a análise de custo/benefício. Essas decisões devem ter parte em uma discussão sobre o que o estado pode fazer, ou seja, as ações precisam ser justificadas segundo uma razão moral (substantive justice);

2 - que os cidadãos acreditem que os demais cidadãos contribuem solidariamente. A disposição de um cidadão em colaborar com o bem comum depende da sua crença de que os outros também tomam parte em um grande número (just distribution of burdens);

3 - que eles considerem que o programa foi organizado levando em conta procedimentos de justiça, o que surge no momento de sua implementação. Por exemplo, os cidadãos podem considerar uma guerra justa, pois podem vê-la como uma guerra defensiva, mas podem, apesar disso, não concordar ou considerar injustos os procedimentos para selecionar qual jovem homem deve lutar (procedural justice). (DeMario, 2013, pp.110, 111)

\section{2) Dos atores à Instituição}

Já uma análise mais preocupada com o papel dos atores, das ideias e dos valores para o entendimento do processo e dos resultados da política retira a ênfase do papel da instituição e se baseia na noção de que as políticas públicas encerram valores sustentados pela sociedade.

Há uma razão simples que nos permite pensar por essa chave que é aquela de que o Estado não age só, são vários os atores e agentes que intervêm e impactam o curso da política.

É importante termos claro o fato de que o debate sobre a relação entre as ideias e as instituições precisa ser mais explorado, mas, a hipótese central, nessa chave, é a de que se queremos entender as instituições e seus resultados é preciso uma abordagem normativa que discuta as ideias, valores e motivações que definem as instituições, em um primeiro momento, e que também serão base para sua avaliação e legitimidade social, em momento posterior.

Trata-se de uma abordagem que conflita com a tradição institucionalista mais dura, para a qual o escrutínio das ideias não permite o desenvolvimento de uma abordagem teórica adequada para a análise das instituições políticas, já que essas são muito mais do que ideias. Um dos autores que busca pensar as instituições a partir das ideias é Rogers Smith.

Smith (2006) defende a sua perspectiva sublinhando que os propósitos, as normas, os papéis e os padrões de comportamento encontrados nas instituições representam encarnações das ideias daqueles que participam delas e que o processo de criação e manutenção das instituições não podem ser entendido de maneira apartada das ideias dos membros das coalizões políticas que dele participam.

Quando preocupações e questões de justiça estão postas, dentro dessa perspectiva de análise, a tarefa se constitui em articular as concepções de justiça sustentadas pelas instituições, e pelas pessoas, para a análise dos resultados e da legitimidade das políticas públicas. Se as políticas públicas são fruto de valores morais definidores de nossas concepções e princípios de justiça socialmente validados e reconhecidos publicamente, o que as justifica perante a sociedade, então a legitimidade da política e a aceitação de seus resultados por parte dos cidadãos é profundamente perpassada por tais valores.

Não se trata de afirmar que as ideias são mais importantes que as instituições, mas sim que há uma complexa relação entre instituições e ideias que não pode ser ignorada. Por mais que as instituições sejam definidoras de valores, e influenciem comportamentos, o outro lado também é verdadeiro, ou seja, os valores sustentados pela sociedade também influenciam na organização e no cotidiano das instituições que precisam se organizar e reorganizar em torno desses valores para se manterem estáveis.

O terreno da legitimidade, de Estados, governos e instituições é demasiadamente movediço. Como identificar tais ideias e sua influência sobre a legitimidade das instituições é outra questão em aberto e difícil de ser enfrentada. Semanticamente, o termo "legitimidade" remete à noção de legalidade, bastaria estar de acordo com a lei para uma instituição ser considerada legítima. Mas o que faz de uma lei legítima? Em última instância, essa é a pergunta que nos importa.

A resposta a essa questão nos leva a um terreno normativo e substantivo que nos convida a indagar sobre as ideias e sua justificação. É em seu sentido substantivo que a legitimidade se liga à justificação (Morris, 2005, p. 156). De início para a construção do argumento trago a definição de justificação proposta por Morris (2005, p.158), o autor afirma que "justificar algo é mostrar que é justo ou certo, razoável, ou, ainda, autorizado; é validar ou provar. [...] Justificar um Estado, então, seria mostrar que seus poderes são justos (ou certos) ou razoáveis". Nesse ponto, Morris adentra a argumentação rawlsiana acerca da justificação, retendo a argumentação de John Rawls sobre a justificação de sua própria teoria.

Nessa passagem, em "Uma Teoria da Justiça”, Rawls ressalta que a discordância é central para a justificação. É no conflito de pontos de vista que buscamos argumentos razoáveis a partir dos quais convencer os outros, buscando reconciliar pela razão.

As políticas públicas são instituições que criam regras para o jogo político, intervêm e moldam as vidas dos cidadãos (Pierson, 2006, p. 114). Precisam, portanto, justificar-se perante esses para que sejam vistas como legítimas e para que os cidadãos possam confiar em suas ações, mais, são regras que para serem seguidas é preciso que confiem que os demais também as aceitam e seguem.

As instituições influenciam o comportamento das pessoas e limitam as escolhas dos atores; como vimos, é comum pensá-las a partir desse ponto de vista, da instituição para os atores, já que essas, dado seu caráter, também são organizações difíceis de se modificar. Entretanto, há momentos históricos, especiais, nos 
quais elas são criadas, e então nos movemos dos atores para as instituições, como coloca Rothstein (1998, p. 138): "Isso significa que o que é racional, socialmente aceito, ou politicamente possível não está dado apenas uma vez e para todos como um axioma, imutável da natureza humana, mas sim pode ser influenciado através da consciência, uma escolha política racional".3

A ideia é a de que no momento da criação das instituições estamos diante de uma escolha racional, consciente, de princípios e de valores que darão origem às instituições.

Entretanto, o foco de Rothstein é outro, e o autor prossegue afirmando que um importante papel das instituições políticas é o de estabelecer normas. Em suas palavras:

A ideia é que as instituições influenciam não somente o que os atores políticos consideram ser um curso racional da ação, a partir de seu próprio ponto de vista, mas também o que eles consideram ser um comportamento moralmente defensável. [...] A moralidade prevalente na sociedade é, em outras palavras, um produto das instituições construídas pelos cidadãos e seus representantes. Minha hipótese, então, é a de que normas sociais não são dadas por alguma entidade metafísica, como "sistema de gênero"; "consciência de classe", ou "caráter nacional. São, ao invés disso, produto das condições institucionais que foram de fato criadas por decisões políticas. (Rothstein, 1998, p.139) ${ }^{4}$

Ou seja, as instituições cumprem importante papel na formação e promoção dos valores em sociedade, o que leva o autor a afirmar que instituições justas incentivariam um comportamento justo. E quando os resultados de uma instituição não são justos? O que a sustenta ao longo do tempo?

No caso brasileiro, as políticas públicas e o Estado que se constituiu com a Constituição de 1988 são fruto de um momento histórico, tal como o que Rothstein chama de especial, no qual os atores, a partir de escolhas racionais, criam as instituições. A premissa aqui é que tais instituições refletem as ideias sustentadas por esses atores e são frutos de um amplo debate para sua justificação no espaço público.

É o processo de construção e avaliação das instituições que se dá a partir da moralidade sustentada pelos atores que delas participam que me interessa.

Dessa forma, é na chave de Smith (2006) que vejo um campo aberto à investigação, para a análise de políticas públicas tanto no que se refere à análise dos resultados, da legitimidade e para a avaliação das políticas públicas. Estou supondo que, mais do que estarem de acordo com a legalidade e com as normas, para que as instituições sejam legítimas é preciso que sejam coerentes com a moralidade sustentada pela sociedade. Se é verdade que elas influenciam e orientam comportamentos, também é verdade que são feitas por pessoas que imprimem nas instituições seus valores, sua moralidade. Dentre aquilo que se estabeleceu como desenho institucional, com suas normas, princípios e objetivos, e os resultados alcançados pela instituição, há um jogo de forças político que pode, ou não, garantir que os resultados sejam coerentes com as metas propostas.
Políticas públicas são o tipo de instituição que estão sob forte influência desse jogo e dos projetos políticos em disputa em seu âmbito e na sociedade de forma mais ampla. Por sua estrutura estão abertas à indeterminação e sujeitas a um constante processo de transformação, seja pelas demandas da sociedade que se alteram em um ritmo mais acelerado do que aquele que a própria instituição é capaz de incorporar, seja por meio da ação dos atores que fazem parte de seu cotidiano que ou aperfeiçoam ou burlam suas normas para realizar os fins da própria instituição, e os seus em particular.

Soma-se a essa discussão a teoria de Rainer Forst, autor ligado a tradição da teoria crítica da justiça, que também chama a atenção para o papel do indivíduo e da moralidade, e para o modo as noções de justiça sustentadas em sociedade influenciam o papel das instituições e a distribuição de bens e recursos e de poder político.

Forst pensa a justiça e formula sua teoria a partir da noção de "direito à justificação". Direito que o autor considera fundamental se o que queremos são sociedades justas, pois se refere ao direito à fala política e à participação nas instituições e que, portanto, deve ser garantido igualmente a todos.

Forst alerta para o fato de que o pensamento acerca da justiça distributiva é, comumente, erroneamente relacionado a certa imagem5 de justiça que se relaciona com a ideia de que devemos dar "para cada um o que lhe cabe, ou é devido na distribuição de bens". Essa visão ignora como os bens são distribuídos e quem determina a estrutura de produção e distribuição; ela negligencia que as demandas por bens são construídas discursivamente em processos de justificação. Por fim, como o foco é a distribuição de bens, perde-se a questão da injustiça, pois as razões da privação não são questionadas e a redistribuição acontece no reino da "ajuda" (Forst, 2014).

Forst (2014) sugere que imaginemos duas situações para as quais a redistribuição de bens se faz necessária: uma é a privação provocada por desastres naturais, a outra é aquela sofrida por aqueles que estão privados dos mesmos bens que aqueles que foram vítimas de um desastre natural, só que sua privação é causada pela exploração político-econômica.

Com toda certeza, ambas as situações são corretamente vistas como casos para os quais a ajuda se aplica. No primeiro caso a ajuda é considerada como um ato de solidariedade moral e no outro como um ato de justiça, sendo que o último se diferencia em razão da privação de uns ser devida a relações de exploração e injustiça e de acordo com os meios que as vítimas possuem para mudar a sua situação. Se essa diferença for ignorada por alguém, esse alguém pode acabar em uma dialética da moralidade, percebendo um ato que é requerido pela justiça como um ato de generosidade. Dessa forma, pessoas autônomas são transformadas de sujeitos em objetos da justiça e, então, em objetos da ajuda e da caridade (Forst, 2014, p. 19).

Para o autor, a vítima da injustiça é aquele que não conta na distribuição de bens em sociedade e por isso a justiça tem um caráter emancipatório. Ao compreender a justiça a partir do direito 
à justificação, é preciso que sejam formulados princípios para a estrutura básica da sociedade que garantam a realização deste direito.

A justiça precisa portanto voltar-se para as relações intersubjetivas e para a estrutura da sociedade e considerar como se dá a justificação das relações e a distribuição do poder de justificação no contexto político. Ou seja, o bem fundamental de uma teoria crítica da justiça é o poder efetivo de demandar, questionar, oferecer justificativa e a partir disso transformar tais reclamos na fundamentação da ação política e dos arranjos institucionais.

Esse bem não é simplesmente "recebido", ele precisa ser construído discursiva e coletivamente.

Forst pensa o homem como um ser justificatório, o que significa que os homens não só têm a habilidade de se justificar como em determinados casos veem a justificação como um dever e esperam o mesmo dos demais. Em sua teoria, o contexto político é o lugar da justificação, conectada normativamente à noção de justiça, e a vítima da injustiça seria aquele que não conta na distribuição de bens em sociedade. O caminho que nos levaria às raízes da injustiça social seria o de considerar a justificação das relações sociais e da distribuição do poder de justificação em contextos políticos.

A justiça é em sua teoria o princípio usado para determinar quais liberdades e formas de igualdade são legítimas.

$\mathrm{O}$ autor define uma teoria da justiça autônoma como aquela que requer como fundamentação o princípio da justificação, tratase de uma teoria que compreende a justiça como uma construção autônoma de sujeitos autônomos. A partir dessa fundamentação, argumenta Forst, é possível construir uma ideia substantiva de direitos humanos como direitos que ninguém poderia negar aos outros.

O princípio da justificação requer para sua realização a reciprocidade e a generalidade; a primeira se define pela ideia de que ninguém recusaria a outrem demandas que faria a si mesmo, e a segunda, a de que as razões para as normas gerais precisam ser compartilhadas por todos que por elas são afetadas.

As razões que justificam demandas morais são aquelas que não seriam razoavelmente rejeitadas.

Razões ou crenças desse tipo surgem da prática mútua e geral de justificação, que constitui um "espaço de justificação"; não se trata de um espaço que contém um estoque de verdades morais determinadas por todos em certo momento, mas sim aquele que é preciso ser sempre reatualizado e novamente validado através de práticas concretas de justificação (Forst, 2012, p. 21).

Tais razões são a base sobre a qual as crenças e as ações se sustentam, bem como são parte do jogo público de explicação. Por isso, elas precisam ser comuns e propiciar a justificação. Em contextos práticos, é preciso distinguir entre uma "base racional" e uma "justificação razoável"; a primeira pode ser compreendida, o que não significa que requeira a aceitação dos outros. Assim, fornecer uma razão significa ser capaz de explicar uma ação, mas não de justificá-la intersubjetivamente. A justificação intersubjetiva só é alcançada se a razão puder ser justificada ética ou moralmente.

\section{Considerações finais}

O objetivo central foi apresentar as razões pelas quais analisar as políticas públicas em aproximação com as teorias da justiça e os pontos por meio dos quais tais teorias contribuem com a análise. Partindo de Rawls até autores que construíram suas teorias e análises a partir do arcabouço teórico rawlsiano, dois caminhos são propostos: um que contém um viés institucionalista voltado para a leitura das normas e padrões institucionais que induzem comportamentos; outro que foca no papel das ideias e da ação política no cotidiano das políticas públicas, questionando o papel das ideias e valores morais sustentados pelos atores diretamente envolvidos com o processo de implementação da política e pela sociedade como um todo, enquanto importante pano de fundo, para a sustentação e legitimidade das políticas ao longo do tempo.

Finalizo sublinhando que, em consonância com a perspectiva defendida por Vita (2008), estou propondo uma leitura na qual as teorias normativas da justiça oferecerem um parâmetro de análise e não uma escala valorativa "dos valores morais e concepções de justiça". A teoria política não tem a pretensão de definir padrões de convívio e leis morais irrefutáveis, por serem a mais perfeita expressão da verdade, que devem ser assumidos pelas sociedades a qualquer preço. Pelo contrário, ela nos fornece elementos que nos são úteis para o questionamento de nossas crenças e valores.

Diferente não poderia ser com a justiça6: é preciso saber identificar quais são os valores centrais de nossa sociedade e de suas instituições, para então confrontá-los com os ideais de uma sociedade justa, sejam eles próximos ou distantes dos nossos, para que possamos compreendê-los, reafirmá-los ou modificá-los.

Álvaro de Vita, na introdução ao livro "O liberalismo igualitário" (2008), coloca que, enquanto teórico político, seu objetivo é fornecer uma perspectiva normativa capaz de examinar teoricamente aquilo que vemos como injustiças patentes e contribuir para esclarecer a natureza da justiça na sociedade, pois sua premissa é a de que as questões políticas do mundo contemporâneo têm um interesse cognitivo. Em seguida, sobre a diferenciação entre a ideologia e teoria política, afirma:

ao passo que a ideologia está mergulhada na luta política e está voltada para o recrutamento de adeptos para uma causa, a atividade da teoria política normativa consiste em oferecer razões - aquilo que denominamos uma justificação - para os julgamentos que fazemos sobre nossos comprometimentos normativos na política Podemos oferecer razões para mostrar uma certa configuração de valores políticos como mais aceitável ou razoável do que outras possíveis e, nesse caso, a discussão teórica vai girar em torno da qualidade dessa justificação. (Vita, 2008, p. 3)

Portanto, ao nos perguntarmos sobre o que deve ou deveria ser, a questão está no grau de correspondência entre teoria e 
realidade - ou seja, entre o universal (definição de valores ou leis válidas universalmente) e o contexto, para usar os termos de Rainer Forst (2010). Trata-se de identificar quais são os pontos de intersecção e/ou distanciamento entre esses dois campos e de determinar o que é razoável e realizável na vida prática.

Ou seja, especificamente para a análise proposta aqui, tratase de olhar para as políticas públicas e questionar sobre os valores e concepções de justiça que as justificam, tomando as teorias da justiça como parâmetro definidor de justo e poder entender se elas estão ou não gerando as condições para que as pessoas realizem suas expectativas de vida.

As teorias normativas da justiça dialogam diretamente com sociedades democráticas cujos princípios centrais baseiam-se na liberdade e na igualdade de seus cidadãos, e mais ainda em democracias propensas à participação direta. $\mathrm{O}$ caso brasileiro congrega tais características. Considero que atualmente nossa questão central não recai mais sobre a necessidade de implementação de instrumentos e instituições que garantam os direitos da cidadania e/ou sobre a formulação e criação de espaços de participação ou políticas públicas com gestão descentralizada, mas sim sobre a efetividade dos instrumentos e instituições implementados pós-1988. A questão recaí, a meu ver, por um lado, sobre os resultados alcançados e a legitimidade das políticas e, por outro lado, sobre a distribuição do poder político e do direito à justificação dentre os cidadãos e atores envolvidos com as políticas públicas, e com os espaços institucionalizados de participação cidadã, instituições nas quais se cruzam burocracia e sua tecnocracia, e as opiniões subjetivas pautadas pelas necessidades reais dos cidadãos.

A política pública é a partir disso pensada como resultante dos valores sustentados em sociedade e que, ao mesmo tempo, precisa ser responsiva aos valores e projetos políticos em disputa que influenciam em sua implementação ao longo do tempo, e são fundamentais para a compreensão de sua legitimidade.

Ou seja, no caso da justiça, é em sua prática diária que a política pública será responsiva às concepções intuitivas de justiça sustentadas pelas pessoas, fundamento de suas demandas e de seus julgamentos.

O pano de fundo dessa discussão é pautado por concepções normativas de justiça que influenciam diretamente nas decisões do gestor sobre a implementação ou não de serviços ou programas específicos, nos diferentes contextos da política, pois é nesse campo de disputa que se colocam em pauta os limites de atuação do Estado via política pública.

Por isso é importante pensar, para além dos procedimentos democráticos e da organização institucional, e procurar conhecer as concepções de justiça articuladas pelas pessoas e as que estão na base das instituições.

Apostamos na democracia como um recurso contra o despotismo e como um instrumento que permite levar em conta as opiniões dos cidadãos no governo, garantindo assim um Estado alinhado à vontade geral. O cidadão é o núcleo da ideia democrática, cidadão entendido como um agente capaz de formular suas opiniões e tomar decisões razoáveis considerando seu contexto e seus objetivos. Nos termos de O'Donnell (2011, p. 43) trata-se de agente "dotado de razão prática e discernimento moral, que usa sua capacidade intelectual e motivação para tomar decisões que, em princípio, são razoáveis em função de sua situação e objetivos".

David Estlund (2008), ao discutir sua noção de democracia epistêmica, chama-nos atenção para o fato de que se queremos que a opinião das pessoas sejam levadas em conta é porque acreditamos que suas opiniões sejam inteligentes; mesmo que elas não tenham um alto nível - em termos de conhecimento técnico e político -, são certamente melhores do que jogar uma moeda na tomada de decisões.

Para Estlund (2008), essa ideia de que o conteúdo da fala das pessoas importa introduz uma dimensão epistêmica à democracia. Cabe a nós então discutir o quanto esse valor epistêmico conta para o grau de autoridade democrática. A dimensão epistêmica remete aos valores morais que são articulados pelas pessoas para a justificativa de seus atos, para as decisões "tomadas" democraticamente e que constituirão a base da legitimidade de uma instituição, ou, das decisões tomadas no âmbito das políticas públicas.

É comum ver no debate do campo democrático a ideia de que o valor dos procedimentos democráticos está no fato de que esses são procedimentos justos e não na qualidade de seus resultados. A questão é que o procedimento justo por si só não tem força para sustentar a legitimidade e a autoridade democrática (Estlund, 2008, p. 83).

O procedimento em si tem pouco a nos dizer sobre os resultados alcançados, melhor, sobre a qualidade dos resultados alcançados. E sobre sua justiça. A leitura pelo viés da justiça precisa levar em conta os princípios socialmente acordados que deverão orientar as relações e ordenar os direitos e deveres dos cidadãos.

Proponho assim uma perspectiva que trabalhe com uma análise substantiva, que considere o valor "epistêmico da democracia" e questione sobre as concepções de justiça articuladas, já que a existência do procedimento ou da instituição não é por si só garantia de resultados justos.

\section{Notas}

${ }^{1}$ Rawls coloca na introdução de "Uma teoria da Justiça" que seu objetivo é apresentar uma "concepção de justiça que generalize e eleve ao mais alto grau de abstração a conhecida teoria do contrato social conforme encontrada em, digamos, Locke, Rousseau e Kant... a ideia norteadora é que princípios de justiça para a estrutura básica da sociedade constituem o objeto do acordo original" (Rawls, 2008, p. 13).

2 Tradução minha, texto original: "(a) First, the basic liberties as given by a list, for example: freedom of thought and liberty of conscience; freedom of association; and the freedom defined by the liberty and integrity of person, as well as by the rule of law; and finally the political liberties; (b) Second, freedom of movement and choice of occupation against a background of diverse opportunities; (c) Third, powers and prerogatives of offices and positions of responsibility, particularly those in the main political and economic institutions; (d) Fourth, income and wealth; and (e) Finally, the social bases of self-respect" (RAWLS, 1999, p. 363).

3 Tradução minha, texto original: "This means that what is rational, socially acceptable, or politically possible is not given once and for all by some true, unchanging human nature, but can be influenced through conscious, rational political choice." 
4 Tradução minha, texto original: "The idea is that institutions not only influence what political actors find to be a rational course of action, seen from the standpoint of their self-interest, but also what they consider to be a morally defensible behavior. [...] The morality prevailing in a society is, in other words, a product of the institutions built by that society's citizens and their representatives. My hypothesis, then, is that social norms are not given by any such metaphysical entities as "the gender system", "class consciousness", or "the national character". They are instead a product of the institutional conditions, which have been created de facto by political decisions" (Rothstein, 1998, p. 139).

${ }^{5}$ Bild no alemão, traduzido para picture em inglês.

6 Considero que, a despeito das críticas ao universalismo da teoria rawlsiana, é possível fazer uma leitura das teorias normativas da justiça, e da teoria da "justiça como equidade", que siga como orientação estabelecer parâmetros de análise que nos auxiliem a identificar tanto as concepções de justiça presentes nas instituições; como aquelas intuitivas, sustentadas pelas pessoas, que são orientadoras da ação social e que se referem aos valores de fundo sustentados por sociedades democráticas.

\section{Referências}

De mario, C. (2013) Saúde como questão de Justiça. Tese de Doutorado. IFCH - UNICAMP, Campinas - SP.

Estlund, David. (2008). Democratic Authority. A Philosophical Framework. Princeton University.

Forst, R. (2012) The Right to justification. Elements of a construtivist theory of justice. NY: Columbia University Press.

. (2014) Justification and Critique. Towards a Critical Theory of Politics. Cambrigde, UK: Polity Press.

(2010) Contextos da Justiça: filosofia política para além de liberalismo e comunitarismo, São Paulo: Boitempo.

Merkel, Wolfgang. (2007) Soziale Gerechtekeit: Theorie und Wirklichkeit. In: www.fesonline-akademie.de.

Morris, C. (2005) Um ensaio sobre o Estado Moderno. SP: Landy Editora.

O'donnell, Guillermo. (2011) Democracia, Agência e Estado. Teoria com intenção comparativa. São Paulo, Paz e Terra.

Pierson, P. (2006) Public Policies as Institutions. In: Rethinking Political Institutions. The art of the state. Org. Ian Shapiro, Stephen Skowronek, Daniel Galvin. (pp.114-131) New York/London: New York University Press.

Rawls, J. (2008) Uma Teoria da Justiça. São Paulo: Ed. Martins Fontes.

Rothstein, B. (1998) Just Instituitions Matter. Cambrigde, United Kingdom: Cambrigde, University Press.

Sarlo, Beatriz. (2005) Tempo presente: notas sobre a mudança de uma cultura. Rio de Janeiro: José Olympo.

Smith, R. (2006) Which comes first, the ideas or the institutions? In: Rethinking Political Institutions. The art of the state. Org. Ian Shapiro, Stephen Skowronek, Daniel Galvin. (pp. 91-113). New York/London: New York University Press, 2006.

Vita, Alvaro de. (2008) O liberalismo igualitário. Sociedade Democrática e justiça internacional. São Paulo: Ed. WMF Martins Fontes. 